\title{
Green building as a target focus in quality and energy efficiency management of construction products
}

\author{
Ekaterina Nezhnikova ${ }^{1}$, Svetlana Uvarova ${ }^{2, *}$, Yana Andryunina ${ }^{2}$, and Lyudmila \\ Myshovskaya $^{2}$ \\ ${ }^{1}$ Moscow State University of Civil Engineering, Yaroslavskoe shosse, 26, Moscow, 129337, Russia \\ ${ }^{2}$ Voronezh State Technical University, Moscow Avenue, 14, Voronezh, 394026, Russia
}

\begin{abstract}
The urgency of the problem of improving the quality of construction products is caused by the need to ensure sustainable development of territories, increase the energy efficiency of buildings and structures, increase the efficiency of investment and construction projects, reduce resource costs, and reduce the negative impact on the environment. The article substantiates the relationship between the quality of construction products and their consumer value, which made it possible to structure the criteria for the quality of construction products and determine the benchmarks in quality management. Taking into account the substantiated criteria for the quality of construction, a methodological toolkit for improving the efficiency of quality management based on a value-oriented approach is proposed. A model has been developed for the efficiency of improving the quality of construction products based on the triad "resource efficiency - minimization of anthropogenic impact - environmental safety for human and nature" until the criteria for green building are achieved.
\end{abstract}

\section{Introduction}

The quality of construction products is a combination of its properties that characterize the consumer value, and most of these properties must comply with regulatory requirements in terms of ensuring safety [1]. Nowadays, the basis for the quality of the final product of construction is the quality of the project, formed by objective engineering surveys and highquality design documentation. It is the design and estimate documentation that formulates the required criteria for the quality of construction work and facilities in accordance with the requirements of regulatory and technical documentation and the specifics of the facility. High-quality performance of work, along with a sufficient level of quality of building materials and structures, ensures the quality of facilities under construction. Ensuring the required level of quality requires building a holistic and adequate modern situation and the specifics of building a quality management system.

An immanent condition for achieving the strategic goals of improving the quality and energy efficiency of the construction industry and housing and communal services is the

*Corresponding author: uvarova_s.s@mail.ru 
development and implementation of management decisions aimed at introducing innovative technologies to improve the quality of design and implementation of construction and installation works, safety of building materials, environmental protection, ensuring environmental well-being of settlements and resource efficiency, the creation of a healthy comfortable living environment, which can only be realized by enhancing the development of green building.

Today, the energy saving trend, initiated by the state, often runs counter to the need to ensure safe and favorable conditions for humans. The dyad "energy efficiency environmental friendliness" is shifting towards energy efficiency. Although, according to the World Health Organization, more than $30 \%$ of all construction sites are subject to contamination with harmful substances [2]. Accordingly, we believe that the criteria for the quality of construction should include the triad "resource efficiency - minimization of anthropogenic impact - environmental safety for human and nature", which corresponds to the essence of green building.

Almost all researchers consider the problem of construction quality to be one of the essential signs of innovativeness of projects, works and objects [3,4]. In this context, innovation in construction should be interpreted as the implementation of the achievements of scientific and technological progress in construction, resulting in an increase in the quality of construction products and economic efficiency, leading to an increase in the systemic competitiveness of organizations that implement innovation [5]. Accordingly, the implementation of green construction projects should be interpreted as a target level of quality and energy efficiency management for a network of enterprises interacting in the process of implementing an investment and construction project.

\section{Materials and Methods}

The minimum limitation in assessing the level of quality in construction should be considered the compliance of the actual values of each of the quality parameters with the normative [1]. The existing system of norms and standards ensures the required level of safety and quality of construction products. By virtue of the adopted methodology for assessing the quality in construction, constant monitoring, adoption and change of technical regulations and standards on a proactive basis in accordance with innovative developments, environmental safety and the usefulness of certain design and construction solutions for the consumer are required.

All criteria for determining the quality of construction products are ultimately based on the value of this product both for the consumer and for the participants in the production pool. The category of value, interrelated with the category of utility, is also interpreted in a broader sense as certain beliefs of individuals or institutional norms. In modern economics, the valuebased approach focuses not only on studying the usefulness of customer value, but is also perceived as value-based management (literally understood as business value management, but actually developed as a management approach to create new value for stakeholders). The creation of value for the consumer unites the action of many actors - stakeholders, including in the creation of construction products.

The researchers substantiated the multidimensionality of consumer value (according to D. Sheth and N. Newman), in which various effects are interconnected, including noneconomic ones. This trend is confirmed by the elements of the concept of sustainable development and greenness systematized by us in paper [2]. Accordingly, the study of the problem of green building as a target in managing the quality of construction products must be carried out from the point of view of a value-based approach both for the consumer and for other stakeholders in construction. 
Based on the conclusions described in the works [6-10], it can be concluded that the implementation of the principles of green building, improvement of the quality parameters of construction facilities, and the introduction of innovations are associated with increased costs. Therefore, taking into account the insufficiently high level of effective demand in Russia and the high degree of competition with conventional construction projects, the requirement for adequate economic profitability of the final and intermediate products of green building is revealed.

In this regard, the aspect of creating innovation of value and quantifying environmental and other additional effects for users of the facility and the environment, interconnected with categories of utility, becomes important.

Ultimately, all the basic conditions for effective quality management in the targeted focusing of the activation of green building are based on the certification system, which is the basis for classifying an object as a green building object in accordance with the provisions of a value-based approach (since it is the value of objects that underlies the criteria certification).

Based on the above substantiation of the normative and value characteristics of the concept of quality, its hierarchical nature and the formation procedure in the process of implementing an investment and construction project, the methodology for forming the effectiveness of construction products (as a result of the implementation of an investment and construction project) as a result of quality management will represent a set of stages of formation and assessment the most important properties and indicators characterized by clear relationships (Fig. 1).

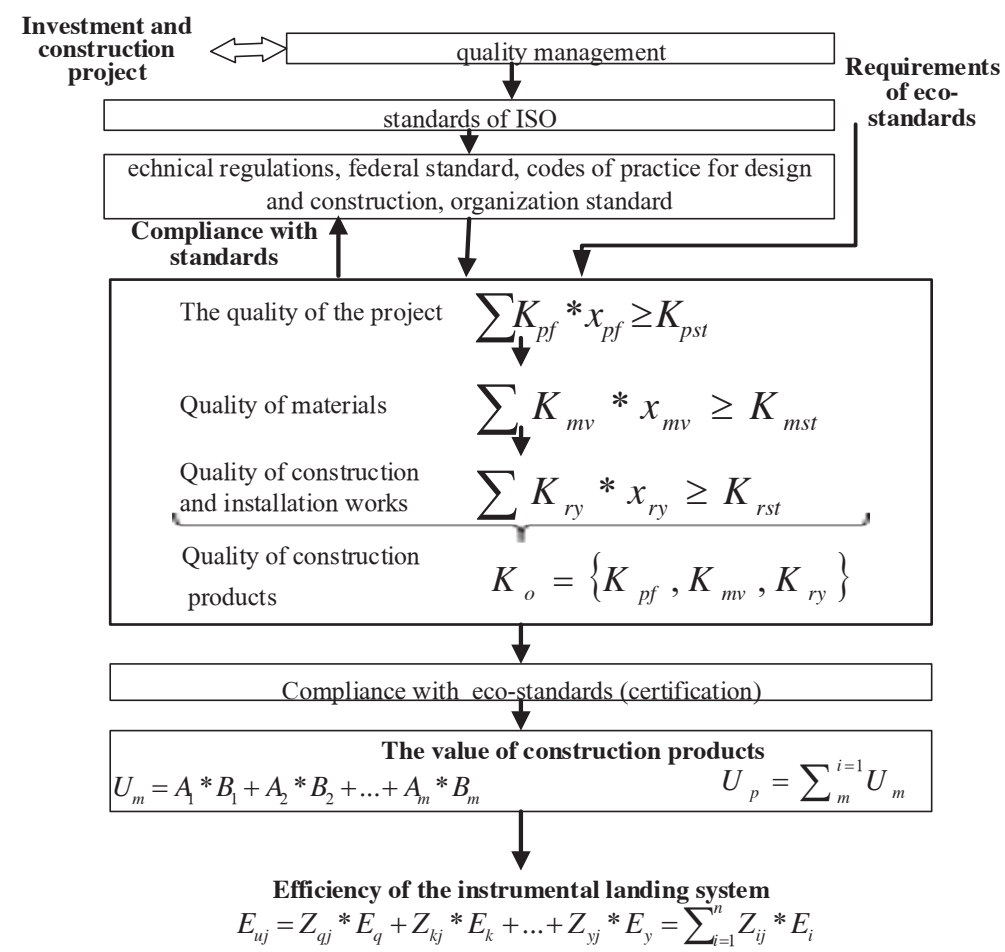

Fig. 1. Methodology for the effective implementation of an investment and construction project as a result of quality management based on criteria for the value of green building 
The developed methodology forms the effectiveness of the implementation of an investment and construction project as a consumer value of a construction object, based on its qualitative characteristics of environmental friendliness, safety, resource efficiency (including energy efficiency), and efficiency is maximized due to the benefit of users that generates demand and is based on the value of the object, depending on the set of its quality criteria. At the same time, value is achieved not only by ensuring the safety of the object, established by compliance with basic norms and standards at all levels and stages of creating construction products, but also, mainly, by ensuring the needs of users achieved by meeting certain environmental standards or requirements for living comfort or the efficiency of the object.

\section{Results}

Based on the author's concept, each investment and construction project, especially a green construction project, or a project with high environmental friendliness or resource efficiency, according to the ESG concept, creates value for stakeholders. Consequently, the efficiency model should be implemented not only in the projection of the life cycle of the creation of construction products, but also in the projection of the creation of stakeholder value (utility). Then the author's logic of modeling can be represented as follows: construction business and operations $\rightarrow$ reduction of possible environmental damage at $j$ stages of the project life cycle $\rightarrow$ utility (value) for i stakeholders $\rightarrow$ economic effect ij. That is, based on the introduction of the category of utility, there is a transformation of the environmental effect into social and, further, into economic one.

Further, it is advisable to assess the criteria for the efficiency of quality management in the target focus of green building for each of the main stakeholders at each stage of the life cycle of the creation of construction products. The efficiency $(E)$ of improving the quality to the level of certified green building was identified by the authors based on the systematization of social, environmental and economic effects and additional costs arising at each stage of the object's life cycle: pre-investment $\left(E_{1}\right)$, investment $\left(E_{2}\right)$, operational $\left(E_{3}\right)$ and disposal $\left(\mathrm{E}_{4}\right)$. At the same time, the effects arising at each stage of the object's life cycle $\left(\Delta \mathrm{E}^{\mathrm{PI}}, \Delta \mathrm{E}^{\mathrm{I}}\right.$, $\Delta \mathrm{E}^{\mathrm{E}}$ ) depend on the value of one or another aspect of green building for a certain stakeholder $\left(\Delta \mathrm{E}=\mathrm{f}\left(\mathrm{E}_{\mathrm{ij}}\right)\right)$ according to the chain "reducing environmental damage - value - effect".

With an increase in the volume of green building, i.e. with the aspiration of the quality management system to manufacture certified construction products as a result of the implementation of investment design, a synergistic effect will be formed, expressed in a decrease in negative consequences for the climate $(\Delta \mathrm{K})$, an increase in the country's energy security $\left(\Delta \mathrm{B}_{\mathrm{e}}\right)$, a decrease in the degree of hazardous waste $(\Delta \mathrm{V})$, and a decrease in their quantity $(\Delta \mathrm{W})$, which will lead to an increase in the level of sustainability of cities and compliance with the conditions for sustainable socio-economic development of the country.

In general, the effect formation model is shown in Figure 2. 
STAGES OF THE OBJECT'S LIFE CYCLE

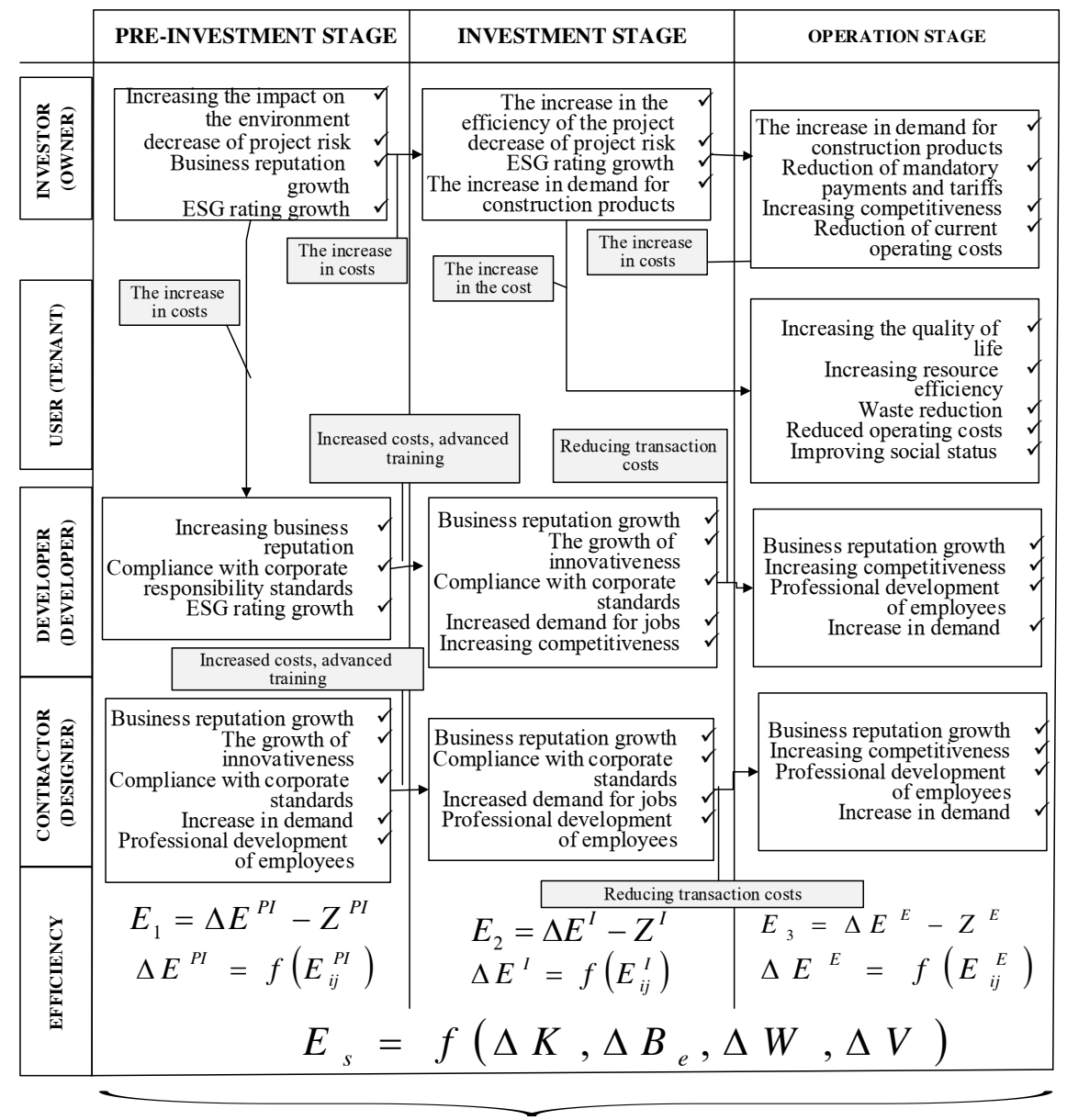

INCREASING VALUE AND QUALITY

Fig. 2. The model of efficiency of improving the quality of construction products to achieve the criteria of green building based on a value-based approach

Next, a model function is formed, in which each effect indicator will correspond to weights according to the utility (value) for the stakeholder.

It should be concluded that the value of improving the quality of construction products to achieve the criteria of green building for each of the stakeholders can be defined as the consumer value of the product, based on the ratio of the effect obtained and the corresponding costs, weighted by the significance of each type of effect for a particular stakeholder (Formula 1):

$$
U_{j}=\sum_{i=1}^{n} Z_{i j} * \frac{W_{i j}}{C_{i j}}
$$

where $U_{j}$ - the value of quality improvement for the $j$-th stakeholder, $Z_{i j}$ - the significance of each type of effect for a specific stakeholder; $W_{i j}$ - the value of the $i$-th effect for the $j$-th stakeholder, $\mathrm{C}_{\mathrm{ij}}$ - costs of the $\mathrm{j}$-th stakeholder to obtain the $\mathrm{i}$-th effect. 
However, speaking of value innovation, one should take into account the specifics of each of the value aspects of green building for each of the stakeholders (given that the level of value of a certain type of effect for each of the stakeholders will be different). Then the integral utility of improving the quality of construction products until the criteria for green building are achieved can be calculated taking into account the influence of stakeholders (formula 2):

$$
U_{u}=\sum_{j=1}^{m} B_{j} * \frac{\sum_{i=1}^{n} Z_{I J} * W_{i}}{C_{j}}
$$

where $U_{u}$ - integral utility of the green construction object; $B_{j}$ - coefficient of influence of the $\mathrm{j}$-th stakeholder; $\mathrm{Z}_{\mathrm{ij}}$ - the significance of each type of effect for a specific stakeholder; $\mathrm{W}_{\mathrm{ij}}-$ the value of the $\mathrm{i}$-th effect for the $\mathrm{j}$-th stakeholder, $\mathrm{C}_{\mathrm{ij}}-\cos$ ts of the $\mathrm{j}$-th stakeholder to obtain the i-th effect.

Similarly, if necessary, it is possible to calculate the effect and value of achieving the criteria for green building at each stage of the life cycle of an investment and construction project.

\section{Discussions}

Determining the value of an object for stakeholders is necessary to select a standard for green certification and quality gradation. Depending on the gradation, the operating efficiency changes throughout the entire life cycle of the building, as well as the degree of the facility's efficiency and the amount of capital investments. Accordingly, the level of certification and value are interrelated, which confirms the above-grounded thesis of certification as the basis for assessing quality when classifying an object as a green building.

Calculation and confirmation of this relationship is very important at the present stage, since the overwhelming majority of experts (K. Agapova, I.L. Vladimirova, etc.) believe that very often the choice of the type and level of certification in the current market situation is dictated by the context of the project (they choose one that is easier and cheaper to implement), rather than the expected value of the project and the quality of construction products.

\section{Conclusion}

Adherence to the proposed methods and recommendations contributes to improving the efficiency of quality management of construction products through value innovation with a target for the development and implementation of investment projects of green building, understanding the relative efficiency of the object and the subject of management from quantitative and qualitative points of view as management efficiency. Accordingly, the calculated substantiation of the efficiency and value of improving the quality of the project until the criteria of green building are achieved for each of the stakeholders characterizes the effectiveness of the management entity, while the improvement in the quality of construction objects to meet green standards and the positive dynamics of the volumes of certified green construction products characterize the efficiency control relative to the object. 


\section{References}

1. S. Uvarova, S. Belyaeva, L. Myshovskaya, IOP Conference Series: Earth and Environmental Science 012169 (2017)

2. Ya. Rogacheva, A. Panenkov, Z. Petrikova, E. Nezhnikova, E3S Web of Conferences, 03037 (2018)

3. I. G. Lukmanova, R. S. Golov, V. G. Smirnov, A. V. Mylnik, Izvestia of higher educational institutions. Textile Industry Technology 2(374), 35-40 (2018)

4. E. Nezhnikova, O. Papelnyuk, M. Dudin, International Journal of Energy Economics and Policy, 9, 172-178 (2019)

5. Kh. M. Gumba, O. M. Belyantseva, L. V. Kochetova, Procedia Engineering, 165, 1323 1327 (2016)

6. M. C. Esteves, D. Dean, M. Balzarova, Sustainable Production and Consumption, 10, 100-109 (2017)

7. R. Golov, V. DIkareva, R. Gorshkov, A. Agarkov, E3S Web of Conferences, 03033 (2018)

8. T. A. Shindina, Quality - Access to Success, 160, 156-161 (2017)

9. I. Ilin, V. Vasilenok, R. Marchenko, Use of renewable energy and tax burden on CO2 emissions in industrial enterprises, E3S Web of Conferences, 110, 0210 (2019)

10. A. Poljanskihh, A. Levina, A. Dubgorn, Investment in renewable energy: Practical case in Estonia, MATEC Web of Conferences, 193, 05065 (2018) 